\title{
International Students Labour and School Attendance: Evidence from China
}

\author{
Edwige Kamitewoko \\ Marien Ngouabi University, Brazzaville, Republic of Congo \\ Email: aijiaae@yahoo.fr
}

How to cite this paper: Kamitewoko, E. (2021). International Students Labour and School Attendance: Evidence from China. Theoretical Economics Letters, 11, 962-977. https://doi.org/10.4236/tel.2021.115061

Received: August 16, 2021

Accepted: October 18, 2021

Published: October 21, 2021

Copyright (C 2021 by author(s) and Scientific Research Publishing Inc. This work is licensed under the Creative Commons Attribution International License (CC BY 4.0).

http://creativecommons.org/licenses/by/4.0/

\begin{abstract}
Since 2000, an increasing number of scholarship international students have been entering Chinese universities. Government scholarships provide them money each month to pay for a degree, but most of them are engaged in part-time work even if china officially doesn't allow international students to work during their studies. This Research aimed to explore the key determinants of international students labour and schooling in China and labour experience contribution to their study. We used the Labor Market Survey (SLM) conducted by LARES (Laboratory of analysis and research in economic and social research) in the year of 2019 in Beijing, Shanghai, Guangzhou, Zhejiang and Shandong. The sample includes 400 scholarship students at the Bachelor, Master and $\mathrm{PhD}$ level. They were from different major areas, aged between 18 and 35 years old. Results from logistic regression analysis showed that developing relationship, practicing Chinese, tutor income, age, were the key factors that influence scholarship international student' work while study. The students benefited both positively and negatively from working and studying.
\end{abstract}

\section{Keywords}

International Students, Labour, School Attendance

\section{Introduction}

Since 2000, an increasing number of scholarship international students have been entering Chinese universities. In 2018 there were a total of 492.185 international students from 196 countries pursuing their studies in 1004 higher education institutions in China's 31 provinces or autonomous regions and many of these students are engaged in part-time work (http://www.moe.gov.cn/, 2019), even if china officially doesn't allow international students to work during their 
studies. Working while studying has become a common practice among students of higher education throughout Chinese province. Watts \& Pickering (2000) notice that various changes in terms of funding mechanism have resulted in increasing numbers of students undertaking employment during their academic studies. Although the exact numbers of students working part-time are difficult to determine, several studies found that between 50 and 60 percent of all university students are engaged in some forms of part-time jobs (Curtis, 2007; HŠkkinen, 2006). Students' places of employment can vary widely depending on the province. Typical employers are school, cinema, fast food restaurants, grocery stress retail stores, and landscaping companies, among others. Some students work during the summer vacations, some work during the school year, and some do both.

Besides, these students every month receive amount of money given by scholarship programs to pay for the studies and take care of them. But why do they work? How does working impact these students? How labor experience contributes to their study?

The relationship between higher education and work has been extensively studied by economists and sociologists (Thune \& Støren, 2015; Støren, Reiling, Skjelbred, Ulvestad, Carlsten, \& Olsen, 2019; Kratz \& Netz, 2018; Jacob, Kühhirt, \& Rodriguez, 2019; Tessema, Ready, \& Astani, 2014; Rokicka, 2014; Bradley, Quigley, \& Bailey, 2021).

From an economic policy perspective, the promotion of part-time work may be an important measure through which the flexibility of labour markets can be increased. On the labour demand side, it may allow employers to adjust hours worked to cyclical conditions more easily, facilitating adjustment of production and labour costs. On the labour supply side, part time work may increase the labour market choices open to individuals and may draw people into the labour market that were previously unwilling or unable to work (Hielke et al., 2004).

While the existing studies that examines the effects and determinants of part-time employment focus on traditional students in their home countries in Europe and America, this area has not been explored in the context of scholarship international students in China.

On the one hand, working during higher education could be viewed as a way to get independence from the family of origin, to early develop knowledge about the "labour market world" and to be socialized to job-related values (Stephenson, 1982; Davies, 1999). Nonetheless, on the other hand, working during university studies may negatively affect academic results, increasing the risk of dropping-out, having a delayed graduation or achieving lower grades. Then, it is necessary to identify influencing factors of student part-time working, examine what happens to the time use of international students in China when they add a job to their daily schedule and explore labour experience contribution to their study. 


\section{Research Objective}

The purpose of this paper is two-fold.

First, the purpose of this study was to determine the factors that push scholarship international student in China to work while studying, in other words, to seek the determinants of international student part-time work supply in China.

Second, to analyze the ways in which international students who are in paid employment manage their study and their employment commitments and how labour experience contributes to their study.

Little is known about international students' labour market participation in China; policy makers and academics have shown little interest in the changed labour market position of students, probably because of the marginal nature of their jobs. Yet, as the following will show, their participation may have added substantially to the "Chinese miracle". Growth in the absolute number of students coupled with an increasing labour market participation, in particular in "marginal" jobs, may add up to a significant number of full-time equivalent jobs. As more students are employed, they face having to balance their academic requirements, extracurricular activities, and employment responsibilities to maintain their lifestyles (Elling \& Elling, 2000).

\section{Significance of the Study}

They are theoretical and practical significances.

\subsection{Theoretical Significance}

What is vitally important is knowing why scholarship international students decide to work and study at the same time and whether or not certain students with more difficulties of learning Chinese language are most affected or if this is a general practice among all scholarship international students.

This research can be used as a reference for someone who wants to do a research in this area as well as it can help to give additional information for other researcher who wants to conduct further research on the related field.

\subsection{Practical Significance}

Knowledge and understanding about the attitudes, perceptions and opinions on which scholarship students base their decisions about paid part-time work and through which they interpret their experiences of engaging in part-time work, has the potential to be used by educators, policy-makers as well as the readers:

For the educators

The result of this research is expected to be useful for the educators as primary data for economic analysis of the international student's workplace; as class or school project topics for investigation, for school level curriculum innovation.

The findings of this study will create better understanding among the public 
and policy makers.

For policy-makers

Understanding motivations and measuring outcomes is important for designing policies for youth that on one hand provide them with support to complete their studies but, on the other, do not diminish the benefits of work. It will also inspire further academic work and hence broaden the frontier of knowledge in the area.

For the readers

Any reader, school staff, teacher, working students, landlord and even student will be able to know and adjust the time of working student and study. we are fore hoping that this study will benefit the readers by determining the student part-time job implications and challenges.

\section{Organization of the Paper}

The rest of the paper is organized as follows: Chapter two highlights the related literature. Chapter three states about the ways in which international students manage their study and work and the impact. Chapter four describes research methodology including description of the study area, sampling techniques, methods of data collection and data analysis. Chapter five explains the result and discussion. The last chapter presents the conclusion

\section{Related Literature}

\subsection{Introduction}

For a better understanding working while studying behavior, this chapter provides the definition of Core Concepts and some highlights of previous research on Working while studying in higher education.

\subsection{Definition of Core Concepts}

\section{Part-Time Work}

For this study, part-time work included any paid work undertaken outside of school hours for an employer. It did not include work experience organized by the school or odd jobs undertaken for the family for pocket money.

International Students-are students who are studying in a country other than their country of origin. This implies that the student is faced with a number of difficulties, often including the necessity of studying and interacting socially and academically in a second language, as well as facing differences in social and academic mores, customs, and expectations. In this study, international students are those from countries other than China, pursuing degrees at a university in China.

School attendance is attendance at any regular accredited educational institution or programme, public or private, for organized learning at any level of education at the time of the census or, if the census is taken during the vacation pe- 
riod at the end of the school year, during the last school year (OCDE, 2001).

\subsection{A Theoretical Review}

The relationship between carrying out working activities during graduation and academic/labour market outcomes has been widely explored by the literature. From a theoretical point of view, there are some benchmarks theories that are related to this issue. In terms of labour market outcomes, human capital theories predict a positive relationship between working while studying and future labour market outcomes, since students' employment increases general and specific human capital through the acquisition of relevant work experience, practical life skills and knowledge (Becker, 1964), which can translate into additional returns on the labour market. According to the Signalling Theory (Spence, 1973), students' work experience can be seen as a strong signal of work motivation, due to the effort of combining work and study.

Social Network Theory (Granovetter, 1973) and Social Capital Theory (Coleman, 1988) predict students' better employment outcomes at career entry due to the linkages students are able to generate while working.

Further, Screening theories stress a positive relationship between students' employment and labour market outcomes since there is an increase in the chance to be employed by the same employer due to on-the-job screening (Stiglitz, 1975). Nonetheless, the same work experience can be seen as a signal of students' liquidity constraint, especially when the performed work is not related to the field of education, which might negatively affect later students' employability (Arrow's, 1973, Statistical Discrimination theory).

In terms of academic outcomes, the benchmark reference can be considered the Theory of the Allocation of Time (Becker, 1965), where it can be inferred a negative impact of employment activities during university on academic performance due to the trade-off between the time dedicated to study and working time. Nevertheless, there might not be necessarily a negative relationship between working and academic achievement in case of an efficient organization of working/studying schedule (such as choice of not compulsory lessons, flexibility in academic planning schedule, etc). Also, the trade-off between working and studying could be reduced by substituting working time with leisure, rather than with hours of study (Dundes and Marx, 2006; Butler, 2007).

\subsection{Empirical Review}

From an empirical point of view, the impact of working while studying on academic or labour market performance has been widely analysed. Concerning academic performance, empirical studies have generally looked at the impact of working while studying on academic achievements in terms of time-to-degree and credits/mark obtained. Using different methodologies and identification strategies in order to take also into account endogenous self-selection into working activities-general findings point out a negative impact of pre-graduation working 
experiences on academic achievements (Theune, 2015; Darolia, 2014; Evans, 2020; Triventi, 2014). Nonetheless, the academic penalization due to working while studying seems to depend on working time, as reported by Darolia (2014) and Body et al. (2014). Their results show that academic achievement is dampened especially when students perform full-time jobs, while the impact of part-time or low-intensity jobs seems to only marginally affect students' academic achievements.

Consistent evidence has been obtained also from studies considering the amount of working hours, which highlight that the negative impact on academic performance increases with work intensity (Wenz and Yu, 2010; Callender, 2008). Hence, the impact of working while studying on academic achievements changes when different working intensities are taken into account.

Key questions in research on student employment usually refer to working students' characteristics and reasons for working during studies (Robert \& Saar, 2012). An important tendency is that not only students from low-income families work during studies, but also those who do not have financial problems (Roshchin, 2006; Beerkens, Magi, \& Lill, 2011; Vosnesenskaya et al., 2001; Alho, 2020). It reflects different motives for student employment.

Concerning the determinant of student part-time working, previous empirical studies provide some evidence on the situation of in-college working in China based on institutional student surveys. They summarize the characteristics of jobs, attitudes and motives of working students, and students' perceptions on gains and losses from working. With regards to the influencing factors of student part-time working, only a few studies have conducted examinations with regression analysis. Using data on marketing majored students in an HEI, Jing, Lyu, and Sun (2010) find that parental attitudes towards part-time working and whether taking student leadership positions in college were positively correlated with the part-time working decision. Zhao \& Qiao (2014) use a dataset of 6 HEIs in Jiangsu Province and find that students' gender, grade, family income, financial aid, and origins were all significantly correlated with their part-time working decisions. Other studies summarize the reasons and motives for students to work. They find that the primary two reasons are to gain social and work experience and to earn monetary compensation (Cheng \& Wang, 2010; Chu et al., 2010; Du, 2015; Song \& Xia, 2020; Yuan, Ren, \& Ouyang, 2009). Other incentives for part-time work include to spend spare time, to make friends, and to follow what other students do (Chu et al., 2010; Li et al., 2011). These findings imply that students' financial need, eagerness to improve labor market competitiveness, time constraints, and peers' influence may be additional factors influencing decisions for part-time working.

There are some knowledge gaps in the current literature. First, most previous studies are descriptive summaries of survey questions concerning national students. There is still a need to examine the influencing factors that push interna- 
tional students in China to part-time work while studying. Second, previous studies are based on data collected from a single or a limited number of institutions. We use the research center data. It is necessary to learn about the situation of scholarship international student part-time working. This paper attempts to fill the knowledge gaps with quantitative analysis.

\section{Scholarship International Student Labor and Schooling in China: The Ways in Which International Students Manage Their Study and Work and the Impact}

China has taken these last years several measures (Providing work permits; several Chinese scholarship programs available for international students, such as the Confucius Institute Scholarship program and local government scholarships. Besides Chinese universities offer many English-taught courses) to attract more international students (Biney and Cheng, 2021). Since Chinese government introducing a number of exploratory changes allowing international students to take part-time jobs in order to make the country's higher educational system more attractive, more students are working in China than ever before.

According to our survey, the types of jobs that students do are commonly: language teacher $36 \%$, Voice recording $18 \%$, Acting $16 \%$, working in bars $13 \%$, nightclubs $9 \%$, restaurants $6 \%$ and retailing $2 \%$. Most of them are in work unrelated to their courses of study. Students working mostly in low-level service and retailing jobs, with low wages. The jobs taken by international students in China sometimes differ according to gender. In retail, for example, girls will be more apt to work at checkouts and in direct customer service, while boys work more as store-hands and shelf-stackers.

\subsection{Positive Contribution of Student Employment}

The participants were asked the positive contribution of working while studying and most of them stated: "I can develop my network of friends and manage my time wisely. I can have more chance to get new ideas in order to enrich my knowledge and Chinese language." "Mainly I am getting experiences from outside the class, how the world works and how to be responsible to ourselves".

By taking part-time jobs, young people gain real-life new experience beyond school. Majority of the students report that their interpersonal and communication skills with Chinese people develop.

Australian student stated: I am a good consumer, but when I arrived in China I didn't know how to demand one goods or service. Only, after six months of Chinese basic course, I got a job and begin to learn about many things. I improved my ability to deal with other people, increased my self-confidence. Besides, the job Helped me to work better as part of a team, enabled me to relate more to what I learn and I organize my time better.

Employment is considered as a networking tool, where students can accumu- 
late contacts for the future and open up the best opportunities for a professional career. The students are happy to learn how to speak the mandarin accent with customers at the work places. They establish contacts in the world of work, cooperate in the workplace with people outside their age group, making more friends, cultural adjustment, get used to trading time against money, take on responsibility, and achieve recognition for what they do. Students have experienced working alongside studies as being useful in developing their oral communication, leadership, and teamwork. In addition to financial reward, a job provides them social gratification. Work accomplished earns young people recognition which is fundamentally different from that routinely accorded at school. Part-time employment are perceived to be enhanced employability, increased confidence in the world of work, greater independence, the improvement of organisational and time management skills.

\subsection{Negative Contribution of Student Employment}

The participants were also asked about how they manage their time in working while studying. Ossy who study at zhejiang university replied: "I try to balance my working hours and study times. How much time I spend for working, I manage my study as well even though I cannot do it fully because I have to do other things. I try to manage my time efficiently by determining when I can study and when I can work. But believe me, it is not easy".

Although these students are happy for the benefits that they gain from working, they also report negative impacts of working on their daily lives. The students' feelings of stress could be attributed to their dual roles (studying and working) conflict and challenging workplace environment. Some of the students feel that they perform physically demanding jobs and that they were not adequately rewarded for the jobs they do. Most of them note unsafe conditions at their work environment. They complained about their exposure to undesirable temperatures and odor.

The others complain about what they perceived as discrimination against them by other co-workers who are American students especially for teaching English. A male student from Asia talked about the difference in salary receive for the same job.

Many students complained about experiencing stress due to time constraint as they have to manage their school work and the job responsibilities.

A female student from Gabon who study at shanghai university shared her conflicts of working while studying says, "You could imagine the past semester, I often woke up every day at 7:00 am or 6:00 am or even earlier to work on my school assignments. By 8:00 am, I was in class. After that I have only couple hours to myself to eat and to do class assignment. I then went to work. After work I would become tired and could not work on my school assignments. Working while studying really reduced time for academic study and assignments". 


\section{Methodology}

\subsection{Sample Selection}

The data used in this paper is from the Student Labor Market Survey (SLM) conducted by LARES (Laboratory of analysis and research in economic and social research) in the year of 2019 in Beijing, Shanghai, Guangzhou, Zhejiang and Shandong province.

Survey data were collected from university international students where efforts were made not only to include students who combine school and work but also international students currently in school and not working.

A total of 400 students were selected, but, only 386 students responded to the survey, they were from 16 higher education institutions (public and private universities). The sample includes scholarship students at the Bachelor, Master and $\mathrm{PhD}$ level.

\subsection{Data Collection Procedure}

Data was collected by trained interviewers using face-to-face interviews with a structured interview schedule (questionnaires) developed by the researchers which comprised of mostly close-ended questions with some open-ended questions. Questions were asked to working and non-working international students. The questionnaire was pilot tested in Laboratory of analysis and research in economic and social research, and the Cronbach alpha tests were carried out to determine the reliability of the questions. Interviewers were trained and a pilot study was conducted to test the validity of questions and to assess the data-collection procedures.

The survey collects information on individual characteristics, family background, university activities, financial situation during their studies, working experiences during their studies, motivation, participation in the paid part-time labour force, strategies used to find a part-time job, use of the wage from their part-time work, the benefits and disadvantages of part-time work, whether having a part-time job influenced their decisions about post compulsory schooling and the desire for suggested relationships between school and part-time work and several other aspects.

Data was collected in late June, July and August 2019, about two months before the commencement in most Chinese universities.

\subsection{Variables}

A number of potential variables for inclusion in the logistic regression are identified on the basis of results of the chi-squared tests and also on the basis of theoretical models, which explain international student's participation in the labor force (Table 1).

\subsection{Model of Logistic Regression}

Logistic model was used to estimate the labour participation equations for 
Table 1. Variables used in regression analysis.

\begin{tabular}{|c|c|c|}
\hline variables & Abbreviations & Coding categories \\
\hline \multicolumn{3}{|l|}{ Dependent variables } \\
\hline work while studying & WWS & $1=$ working while studying and $0=$ otherwise \\
\hline \multicolumn{3}{|l|}{ Independent variables } \\
\hline Age & YEAR & a continuous variable \\
\hline Financial needs & FN & $\begin{array}{l}1 \text { if the international student has enough money } \\
\text { to respond to financial needs and } 0 \text { otherwise }\end{array}$ \\
\hline Tutor work pattern & TWP & $\begin{array}{l}1 \text { if a tutor participates in the labour market and } \\
0 \text { otherwise }\end{array}$ \\
\hline Tutor income & TI & a continuous variable \\
\hline Practicing Chinese & $\mathrm{PC}$ & $\begin{array}{l}1 \text { if the international student speaks Chinese and } \\
0 \text { otherwise }\end{array}$ \\
\hline Develop relationship & $\mathrm{DR}$ & $\begin{array}{l}1 \text { if the international student developed } \\
\text { relationships and } 0 \text { otherwise }\end{array}$ \\
\hline Gain experience & GE & $\begin{array}{l}1 \text { if the international student gain experience and } \\
0 \text { otherwise }\end{array}$ \\
\hline Student earning & SE & 1 if a salary is attractive 0 otherwise \\
\hline Children & $\mathrm{CHI}$ & $\begin{array}{l}1 \text { if the international student has children in } \\
\text { China or in origin country and } 0 \text { otherwise }\end{array}$ \\
\hline
\end{tabular}

international student.

For the logistic model with more than one independent variable, the model can be written as:

Prob. [an international student is in the workforce or combining work and study]:

$$
P[y=1]=\frac{\mathrm{e}^{z}}{1+\mathrm{e}^{z}}
$$

An equivalent form is:

$$
\frac{\mathrm{e}^{z}}{1+\mathrm{e}^{z}}=\frac{1}{1+\mathrm{e}^{-z}}
$$

where $Z$ is a linear function of the explanatory variables. If $X_{1}, X_{2}, \cdots, X_{k}$ are the respondent characteristics and their family characteristics, then " $Z$ ' equation is as follows:

$$
Z=\beta_{0}+\beta_{1} X_{1}+\beta_{2} X_{2}+\cdots+\beta_{k} X_{k}
$$

$X_{i}$ is $i$ th explanatory variable $(i=1,2, \cdots, k) ; \beta_{i}$ are parameters of the model $(i=0,1,2, \cdots, k)$.

Under this model, the probability that an international student with a given set of characteristics is not in the work force is given by:

$$
P[y=0]=1-P[y=1]=: \frac{\mathrm{e}^{-z}}{1+\mathrm{e}^{-z}}=\frac{1}{1+\mathrm{e}^{z}}
$$




\section{Result and Interpretation}

The logit regression result that is aimed at examining the determinants of scholarship international student labour participation is presented below (Table 2).

Logistic regression Number of obs $=389$

LR $\operatorname{chi} 2(9)=45.53$ Prob $>$ chi $2=0.0000$

Log likelihood $=-35.044563$ Pseudo R2 $=0.3938$

Results from logistic regression analysis showed that develop relationship, practicing Chinese, tutor income, age; were the key factors that influence students' work while study.

The sign of the $\mathrm{B}$-values $(\beta)$ shows whether a variable has a positive or negative effect on employment. And "B" $(\beta)$ values show positive or a negative association between students employment status and each variable.

\subsection{Develop Relationships}

There is a positive relationship between develop relationship and student labour force participation. As many empirical studies have revealed (Lall, 2017; Han, 2016), relationships are everything in China. The Chinese call this guanxi (关 系). Guanxi building is future favor exchanges between parties tied by mutually recognized guanxi. In short, guanxi culture legitimizes the expected obligations to provide a favor to someone when it is sought after through a guanxi tie; such a reciprocal outcome is an unintended consequence of social networking in Western cultures, in which no social capital would be generated by deliberate network building for instrumental values (Arrow, 1998). Guanxi refers to having personal trust and a strong relationship with someone, and can involve moral obligations and exchanging favours. Guanxi is neither strictly business nor personal. It relies

Table 2. Logit regression for scholarship international student participation in the labor market.

\begin{tabular}{ccccc}
\hline Student participation & Coef. & Std. Err & $Z$ & $P>|z|$ \\
\hline Age & -3.482486 & 1.145607 & $-3.04^{*}$ & 0.002 \\
children & -0.0127553 & 0.215002 & -0.59 & 0.553 \\
develop relationship & 0.5660326 & 0.1872876 & $3.02^{*}$ & 0.003 \\
Tutor work pattern & 29.47918 & 8.06343 & 3.01 & 0.001 \\
Tutor income & -3.020461 & 1.190427 & $-2.54^{*}$ & 0.011 \\
financial needs & -0.6809934 & 0.687956 & 0.99 & 0.322 \\
practicing Chinese & 2.177998 & 1.00529 & $2.17^{*}$ & 0.030 \\
Student earning & -1.036897 & 1.145607 & -0.91 & 0.364 \\
Gain experience & 0.0155558 & 0.2045547 & 0.88 & 0.939 \\
Cons & 30.47918 & 10.06343 & 3.03 & 0.002
\end{tabular}

Coefficients with $*$ denote significance at $95 \%$ confidence interval. Source: Computations from LARES Survey, 2019. 
on a blend of emotional and instrumental ties between people, including demonstrations of both personal caring and the mutual ability to provide solutions. Relationships can be aided and built by some general knowledge of China and its culture. This can assist to establish an immediate connection to a new Chinese contact. Building positive workplace relationships is vital for career success. When you build positive relationships, you feel more comfortable with your interactions and less intimidated by others. Hence, guanxi plays a crucial role in the build-up of economic ties in China. Having good, bad or no guanxi impacts one's influence and ability to get things done.

Guanxi is a branch of Chinese culture. The international students develop guanxi on working to immerse in Chinese culture.

\subsection{Practicing Chinese}

"Practicing Chinese" impact positively student labor participation. One of the biggest challenges faced by international students in China is the Chinese language (Mandarin) barrier. It is the most common spoken language amongst the Chinese throughout the world. It is essential to clarify that there was also awareness that competence in Chinese is not simply a matter of vocabulary and rules of grammar: there is also an important cultural dimension. If students lack the relevant cultural schemata or frames of reference, their understanding will be impaired. Working is among tools that allow international students to integrate into the new cultural environment and felt unacceptable by the locals.

"Huayu" (Chinese language) in South-east Asian countries such as Malaysia and Singapore.

Students are deeply enthusiastic about the new living and learning environment and were novel about everything around them. After a basic knowledge in Chinese, they launch in part-time job.

\subsection{Age}

Age affects negatively students' entering into the labour force while studying.

Most younger students are considered to be of core working-age because of their strong attachment to the labor market. Older student are less likely to work.

\subsection{Tutor Income}

Tutor income is negatively correlated with student part-time work. More the tutor income is higher, less his child (student) is interesting in part-time work.

\section{Conclusion}

This paper investigated the determinant of working while studying for scholarship international students.

The results show that Guanxi is one of the driving forces of working while studying where in they want to develop relations Guanxi, establish an immediate 
connection to a new Chinese contact. Because Building positive workplace relationships is vital for career success. Practicing Chinese is also a driving force. They want to improve themselves in Chinese language and getting language experience that they could possibly use in the future. Most of the reason why students work is to develop relations "Guanxi". This serves as an internal motivation for students to work more even though they are studying as well because build positive relationships. Age and tutor income impact negatively student work while studying.

The working while studying program should be widely provided to help student get hand-on experiences.

\section{Conflicts of Interest}

The author declares no conflicts of interest regarding the publication of this paper.

\section{References}

Alho, R. (2020). "You Need to Know Someone Who Knows Someone": International Students' Job Search Experiences. Nordic Journal of Working Life Studies, 10, 3-22. https://doi.org/10.18291/njwls.v10i2.120817

Arrow, K. (1998). What Has Economics to Say about Racial Discrimination. Journal of Economic Perspectives, 12, 91-100. https://doi.org/10.1257/jep.12.2.91

Arrow, K. J. (1973). The Theory of Discrimination. In O. Aschenfelter, \& A. Rees (Eds.), Discrimination in Labor Markets (pp. 3-42). Princeton University Press.

Becker, G. S. (1964). Human Capital: Atheoretical and Empirical Analysis, with Special Reference to Education. Colombia University Press.

Becker, G. S. (1965). A Theory of the Allocation of Time. The Economic Journal, 75, 493-517. https://doi.org/10.2307/2228949

Beerkens, M., Mägi, E., \& Lill, L. (2011). University Studies as a Side Job: Causes and Consequences of Massive Student Employment in Estonia. Higher Education, 61, 679-692. https://doi.org/10.1007/s10734-010-9356-0

Biney, P., \& Cheng, M. (2021). International Students' Decision to Study in China: A Study of Some Selected International Students from Universities in China. Open Journal of Social Sciences, 9, 305-325. https://doi.org/10.4236/jss.2021.98021

Body, K. M. D., Bonnal, L., \& Giret, J. F. (2014). Does Student Employment Really Impact Achievement? The Case of France. Applied Economics, 46, 3061-3073. https://doi.org/10.1080/00036846.2014.920483

Bradley, A., Quigley, M., \& Bailey, K. (2021). How Well Are Students Engaging with the Careers Services at University? Studies in Higher Education, 46, 663-676. https://doi.org/10.1080/03075079.2019.1647416

Butler, A. B. (2007). Job Characteristics and College Performance and Attitudes: A Model of Work-School Conflict and Facilitation. Journal of Applied Psychology, 92, 500-510. https://doi.org/10.1037/0021-9010.92.2.500

Callender, C. (2008). The Impact of Term-Time Employment on Higher Education Students' Academic Attainment and Achievement. Journal of Education Policy, 23, 359-377. https://doi.org/10.1080/02680930801924490 
Cheng, Q., \& Wang, S. (2010). Investigation and Analysis on Work-Study among College Students (in Chinese). Journal of Changchun University of Science and Technology (Higher Education Edition), 5, 18-19.

Chu, B., Yang, L., \& Ma, Q. (2010). Investigation and Analysis of Part-Time Working among College Students (in Chinese). Market Modernization, No. 615, 76.

Coleman, J. S. (1988). Social Capital in the Creation of Human Capital. The American Journal of Sociology, 94, S95-S120. https://doi.org/10.1086/228943

Curtis, S. (2007). Students' Perceptions of the Effects of Term-Time Paid Employment. Education + Training, 49, 380-390. https://doi.org/10.1108/00400910710762940

Darolia, R. (2014). Working (and Studying) Day and Night: Heterogenous Effect of Working on the Academic Performance of Full-Time and Part-Time Students. Economic of Education Review, 38, 38-50. https://doi.org/10.1016/j.econedurev.2013.10.004

Davies, P. (1999). Half Full, Not Half Empty: A Positive Look at Part-Time Higher Education. Higher Education Quarterly, 53, 141-155. https://doi.org/10.1111/1468-2273.00120

Du, J. (2015). An Analysis of College Students' Taking Part-Time Jobs: Taking Anhui Xinhua University as an Example. Journal of Anhui Agricultural University (Social Sciences Edition), 24, 119-121. (In Chinese)

Dundes, L., \& Marx, J. (2006). Balancing Work and Academics in College: Why Do Students Working 10 - 19 Hours Per Week Excel? Journal of College Student Retention, 8, 107-120. https://doi.org/10.2190\%2F7UCU-8F9M-94QG-5WWQ

Elling, S. R., \& Elling, T. W. (2000). The Influence of Work on College Student Development. NASPA Journal, 37, 454-470. https://doi.org/10.2202/1949-6605.1108

Evans, C. (2020). Exploiting Students' Part-Time Work to Enhance Learning, Teaching and Assessment. Industry and Higher Education, 35, 10-13.

https://doi.org/10.1177/0950422220930182

Granovetter, M. S. (1973). The Strength of Weak Ties. American Journal of Sociology, 78, 1360-1380. https://doi.org/10.1086/225469

Han, R. (2016). Discussion on Relationship between Guanxi and Corruption in China. British Journal of Economics, Management \& Trade, 14, 1-9. https://doi.org/10.9734/BJEMT/2016/27577

Hielke, B., Gilles, M., \&, Melanie, W. (2004). The Determinants of Part-Time Work in EU Countries: Empirical Investigations with Macro-Panel Data. Discussion Paper No. 1361.

HŠkkinen, I. (2006). Working While Enrolled in a University: Does It Pay? Labour Economics, 13, 167-189. https://doi.org/10.1016/j.labeco.2004.10.003

Jacob, M., Kühhirt, M., \& Rodriguez, M. (2019). Labour Market Returns to Graduates' International Experience: Exploring Cross-Country Variations in Europe. European Sociological Review, 35, 491-505. https://doi.org/10.1093/esr/jcz022

Jing, Z., Lyu, J., \& Sun, X. (2010). Part-Time Working Behavior and Its Determinants among Students Majored in Marketing (in Chinese). Higher Agriculature Education, 5, 73-77.

Kratz, F., \& Netz, N. (2018). Which Mechanisms Explain Monetary Returns to International Student Mobility. Studies in Higher Education, 43, 375-400. https://doi.org/10.1080/03075079.2016.1172307

Lall, R. (2017). Jared Kushner Has Wasta. 
http://www.thearabweekly.com/Opinion/7558/Jared-Kushner-has-wasta

Li, L., Yang, Li., Chen, Y., Wang, T., \& Sun, L. (2011). Investigation and Analysis of the Current Situation of Working College Students (in Chinese). China Electronic Power Education, No. 32, 169-170.

OCDE (2001). Glossary of Statistical Terms, Education and Training Statistics Principles and Recommendations for Population and Housing Censuses, Revision 1, United Nations, New York.

Robert, P., \& Saar, E. (2012). Learning and Working: The Impact of the "Double Status Position" on the Labour Market Entry Process of Graduates in CEE Countries. European Sociological Review, 28, 742-754. https://doi.org/10.1093/esr/jcr091

Rokicka, M. (2014). The Impact of Students' Part-Time Work on Educational Outcomes. ISER Working Paper Series 2014-42, Institute for Social and Economic Research.

Roshchin, S. Y. (2006). The School-to-Work-Transition: A Slough or a Ford? Working Paper WP3/2006/10. State University-Higher School of Economics, 52 p. (in Russian).

Song, Y., \& Xia, J. (2020). Scale Making in Intercultural Communication: Experiences of International Students in Chinese Universities, Language, Culture and Curriculum. Language, Culture and Curriculum. https://doi.org/10.1080/07908318.2020.1857392

Spence, M. (1973). Job Market Signaling. Quarterly Journal of Economics, 87, 355-374. https://doi.org/10.2307/1882010

Stephenson, S. P. (1982). Work in College and Subsequent Wage Rates. Research in Higher Education, 17, 165-178. https://doi.org/10.1007/BF00973717

Stiglitz, J. E. (1975). The Theory of "Screening", Education, and the Distribution of Income. American Economic Review, 65, 283-300.

Støren, L. A., Reiling, R. B., Skjelbred, S.-E., Ulvestad, M. E., Carlsten, T. C., \& Olsen, D. S. (2019). Utdanning for arbeidslivet. Arbeidsgivers forventninger til og erfaringer med nyutdannede fra universiteter, høgskoler og fagskoler. [Education for Working Life]. Report 3. Oslo: NIFU.

Tessema, T. M., Ready, J. K., \& Astani, M. (2014). Does Part-Time Job Affect College Student's Satisfaction and Academic Performance (GPA). International Journal of Business Administration, 5, 50-59. https://doi.org/10.5430/ijba.v5n2p50

Theune, K. (2015). The Working Status of Students and Time to Degree at German Universities. Higher Educatio, 70, 725-752. https://doi.org/10.1007/s10734-015-9864-Z

Thune, T., \& Støren, L. A. (2015). Study and Labour Market Effects of Graduate Students' Interaction with Work Organizations during Education: A Cohort Study. Education + Training, 57, 702-722. https://doi.org/10.1108/ET-10-2014-0126

Triventi, M. (2014). Does Working during Higher Education Affect Students' Academic Progression? Economic of Education Review, 41, 1-13.

https://doi.org/10.1016/j.econedurev.2014.03.006

Vosnesenskaya, E. D., Konstantinovsky, D. L., \& Cherednichenko, G. A. (2001). Finish the Course and Get a Place": A Study of Students in Secondary Employment. Journal of Sociology, No. 3. (In Russian)

Watts, C., \& Pickering, A. (2000). Pay as You Learn: Student Employment and Academic progress. Education \& Training, 42, 129-135. https://doi.org/10.1108/00400910010372670

Wenz, M., \& Yu, W. C. (2010). Term-Time Employment and the Academic Performance of Undergraduates. Journal of Education Finance, 35, 358-373.

https://doi.org/10.1353/jef.0.0023 
Yuan, Y., Ren, C., \& Ouyang, K. (2009). Investigation and Analysis of College Students' Work-Study Participation. Success, No. 4, 226. (In Chinese)

Zhao, B., \& Qiao, X. (2014). The Current Situtation and Influencing Facotrs of College Students' Part-Time Job. Contemporary Youth Research, No. 3, 58-63. (In Chinese) 